\title{
Rancang Bangun Protoype Robot Navigasi Pemadam Api di Bandar Udara
}

\author{
Sunardi ${ }^{1,2}$, Julfansyah Margolang ${ }^{3}$, Jhoni Hidayat ${ }^{4}$, Iswandi Idris ${ }^{5,}$, Rizaldy Khair ${ }^{5}$ \\ ${ }^{1}$ Teknologi Pemeliharaan Pesawat Udara, Politeknik Penerbangan Medan, Indonesia \\ ${ }^{2}$ Mahasiswa Doktoral Fisika, Universitas Sumatera Utara, Medan \\ ${ }^{3}$ Pemanduan Lalu Lintas udara, Politeknik Penerbangan Medan, Indonesia \\ ${ }^{4}$ Teknik Telekomunikasi Dan Navigasi Udara, Politeknik Penerbangan Medan, Indonesia \\ ${ }^{5}$ Teknologi Komputer, Politeknik LP3I Medan, Indonesia \\ Email: 1'sunardi.adi22@yahoo.co.id,3julfan@atkp-medan.ac.id, 4,*iswandi.idris@plm.ac.id, 5rizaldyk.lp3i@gmail.com \\ Email Penulis Korespondensi: iswandi.idris@plm.ac.id
}

\begin{abstract}
Abstrak-Dalam teknik penerbangan maka Keselamatan Penerbangan harus menjadi perhatian exktra bagi pemerintah sebagai regulator/fasilitator, setiap komponen sub system Bandar udara dalam melakukan kegiatan operasinya tetap harus mengutamakan keamanan dan keselamatan penerbangan Dalam hal ini komponen pendukung dan pemanfaatan teknologi AI di rasakan sangat perlu guna melengkapi kebutuhan akan Pemenuhan Keselamatan Penerbangan dengan memanfaatkan robot sebagai media. Secara umum robot dapat didefinisikan sebagai sebuah piranti mekanik yang mampu melakukan pekerjaan manusia atau berperilaku seperti manusia. Salah satu pekerjaan manusia yang dapat dilakukan oleh robot adalah kegiatan pemadaman kebakaran. Dalam penelitian ini peneliti merancang sebuah Robot Pemadam Api untuk mencari dan memadamkan api, Perancangan pada robot ini menggunakan sensor ultrasonik HC-SR04 sebagai parameter jalannya robot ketika adanya objek disekitar dan modul sensor api sebagai pendeteksi adanya api robot ini menggunkan servo MG995 yang berguna sebagai pengontrol selang dari pompa air. Rangkaian pada robot ini memiliki komponen-komponen yang penting yaitu mikrokontroler Arduino berfungsi sebagai otak dari robot dan Driver Motor Shield L298P berfungsi sebagai modul penggerak Motor DC. Apabila robot mendeteksi adanya api saat berjalan maka robot akan berhenti dan memadamkan api menggunakan air dan lilin digunakan sebagai simulasi api saat sedang terjadinya kebakaran.
\end{abstract}

Kata Kunci: Robot Pemadam Api, Arduino Uno R3, Sensor Api, Sensor Ultrasonik

\begin{abstract}
In aviation engineering, Aviation Safety must be an extreme concern for the government as a regulator / facilitator, each component of the Airport sub-system in conducting its operations must still prioritize flight safety and safety. In this case the supporting components and the utilization of AI technology are felt to be very necessary in order to complete the needs will Fulfill Flight Safety by utilizing robots as a medium. In general, robots can be defined as a mechanical device that is able to do human work or behave like humans. One of the human jobs that can be done by robots is fire fighting activities. In this study, researchers designed a Fire Extinguisher Robot to find and extinguish fire. The design of this robot uses an ultrasonic sensor HC-SR04 as a parameter for the robot's path when there are objects around and a fire sensor module as a detector for the presence of fire this robot uses MG995 servo that is useful as a controller hose from the water pump. The circuit in this robot has important components, the Arduino microcontroller functions as the brain of the robot and the L298P Motor Shield Driver functions as a DC motor drive module. If the robot detects a fire while walking, the robot will stop and extinguish the fire using water and candles are used as a fire simulation when a fire is happening.
\end{abstract}

Keywords: Fire Extinguisher Robot, Arduino Uno R3, Fire Sensor, Ultrasonic Sensor

\section{PENDAHULUAN}

Dalam teknik penerbangan maka Keselamatan Penerbangan harus menjadi perhatian exktra bagi pemerintah sebagai regulator/fasilitator, setiap komponen sub system Bandar udara dalam melakukan kegiatan operasinya tetap harus mengutamakan keamanan dan keselamatan penerbangan Dalam hal ini komponen pendukung dan pemanfaatan teknologi AI di rasakan sangat perlu guna melengkapi kebutuhan akan Pemenuhan Keselamatan Penerbangan dengan memanfaatkan robot sebagai media. Secara umum robot dapat didefinisikan sebagai sebuah piranti mekanik yang mampu melakukan pekerjaan manusia atau berperilaku seperti manusia. Robot adalah sebuah alat mekanik yang dapat melakukan tugas fisik, baik menggunakan pengawasan dan kontrol manusia, ataupun menggunakan program yang telah didefinisikan terlebih dulu (kecerdasan buatan) [1]. Salah satu pekerjaan manusia yang dapat dilakukan oleh robot adalah kegiatan pemadaman kebakaran. Kebakaran sering sekali terjadi, dalam hal ini dibutuhkan sebuah perangkat pendukung untuk mencegah yaitu robot. Robot dapat mencegah suatu bencana terutama pada bencana kebakaran sering sekali terjadi kebakaran dan tidak bisa diantisipasi, dalam hal ini robot pemadam api sangat membantu dalam menanggulangi bencana kebakaran. Pada penelitian ini peneliti akan membuat robot pencegahan bencana, yaitu Robot pemadam api menggunakan media air. Microcontroller adalah komputer yang berukuran mikro dalam satu chip IC (integrated circuit) yang terdiri dari processor, memory, dan antarmuka yang bisa diprogram) [2]. Arduino adalah pengendali mikro single-board yang bersifat open-source, diturunkan dari Wiring platform, dirancang untuk memudahkan penggunaan elektronik dalam berbagai bidang [3]

Sudah banyak penelitian sebelumnya tentang robot pemadam api, seperti Fire-Extinguishing Robot Design by Using Arduino [4] . Penelitian ini menggunakan sensor MZ80 dan Bluetooth sebagai alat control melalui mobile. Perancangan Robot Cerdas Pemadam Api Dengan Sensor Thermal Array TPA 81 Berbasis 
Microcontroller Arduino MEGA 2560 [5]. Robot pemadam api ini dapat mendeteksi api pada jarak 1,8 m dan dapat memadamkan api dalam waktu rata-rata 20 detik.

Berbeda dengan penelitian sebelumnya disini peneliti menggunakan media air untuk memadamkan api. Dan pada penelitian ini Robot Pemadam Api dirancang menggunakan mikrokontroler Arduino Uno R3 [6]. Sensor HC-SR04 untuk mendeteksi adanya halangan didepan robot maka robot akan mencari jalan yang tidak ada halangannya, dan disini peneliti menggunakan Servo untuk menggerakan selang air kekiri dan kekanan dan sensor api untuk mendeteksi adanya api

\section{METODE PENELITIAN}

\subsection{Lokasi Penelitian}

Penelitian ini dilaksanakan di ATKP Medan, JL. Penerbangan No.85 Jamin Ginting Km. 8,5. Padang Bulan, Medan, 20131.

\subsection{Rancangan Penelitian}

Rancang penelitian dari Rancang Bangun Robot Pemadam Api Menggunakan Medai Air terbagi menjadi beberapa bagian perancangan antara lain:

\subsubsection{Rancangan Blok Diagram}

Rancangan Blok Diagram Robot pemadam api ini memili 3 bagian yaitu bagian input, proses, output. Bagian input terdiri dari baterai, sensor ultrasonik, dan sensor api, bagian proses hanya ada mikrokontroler Arduino dan bagian output terdiri dari pompa air dc, motor $d c$, dan motor servo. Berikut rancangan Blok Diagram robot:

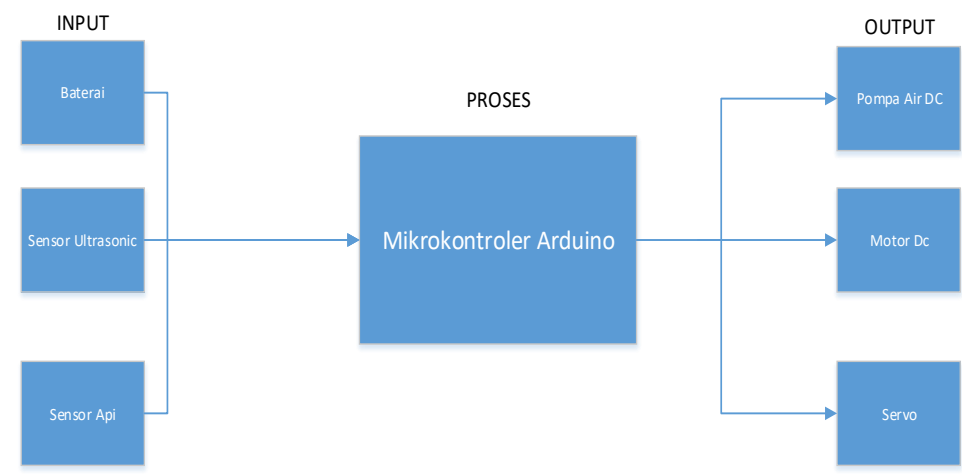

Gambar 1. Blok Diagram Robot

\section{HASIL DAN PEMBAHASAN}

Rancangan Robot Pemadam api memiliki beberapa bagian yaitu Mikrokontroler Arduino R3, Flame Sensor, Servo, Pompa Air DC, L298P Motor DriverL298P, Motor DC, Sensor Ultrasonik HC-SR04. Setiap komponen memiliki perannya masing-masing dan saling terhubung satu sama lain. Berikut rancangan robot yang telah dibuat peneliti:

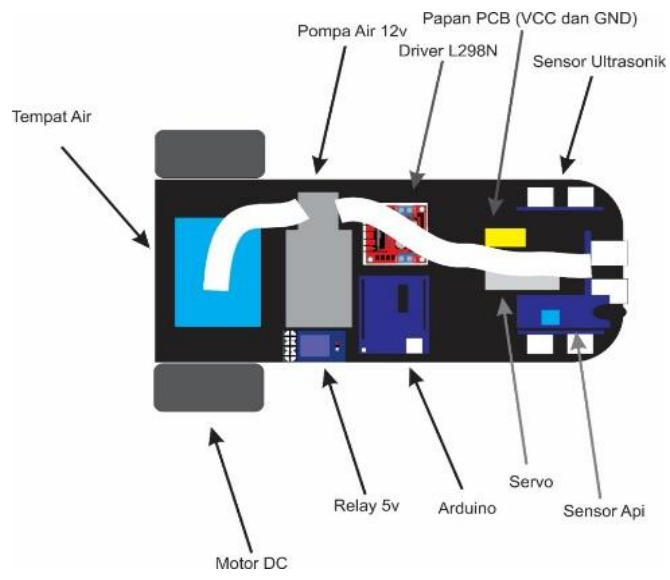

Gambar 2. Rancangan Robot 
Rancangan pengkabelan robot sangatlah penting sebab disini peneliti dapat menimalisir kerusakan atau konsleting pada robot. Dalam merancang pengkabelan pada robot peneliti menggunakan Software Fritzing, Berikut hasil perancangan pengkabelan robot:

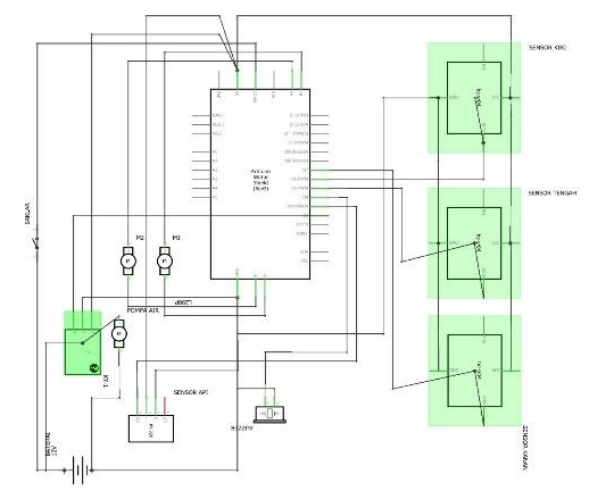

Gambar 3. Rancangan Pengkabelan Robot

\subsection{Uji Coba Robot}

Pada bagian ini peneliti akan menjeleskan dari uji robot yang telah dilakukan pada uji coba ini peneliti melakukan beberapa tahap uji coba untuk mendeteksi api yaitu:

\section{Tahap Pertama}

Tahap pertama robot diuji navigasinya menggunakan sensor UltrasonikHC-SRO4 untuk mendeteksi adanya objek dan menghasilkan bahwa robot akan mendeteksi adanya objek dalam jarak sensor jarak dibagi 3 bagian yaitu kiri, kanan dan tengah masing-masing jarak deteksi $18 \mathrm{~cm}$, jika sensor kiri dan tengahmendeteksi adanya objek maka robot akan berbelok kanan.

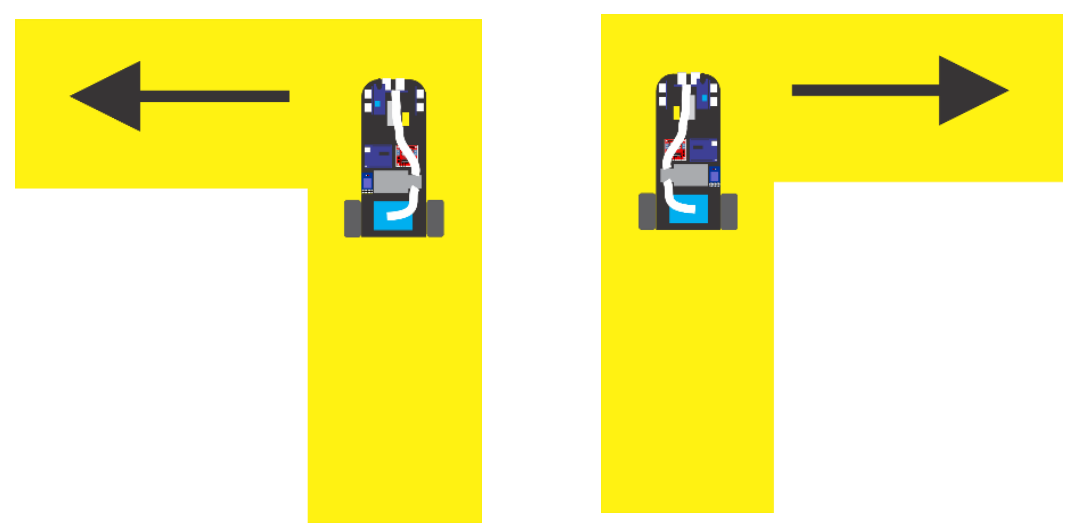

Gambar 4. Sensor kiri dan kanan robot belok kiri dan Sensor kanan dan tengah robot belok kiri

Jika sensor kanan dan tengah mendeteksi adanya objek maka robot akan berbelok kiri, Jika sensor tengah mendeteksi adanya objek maka robot akan berbelok kanan.
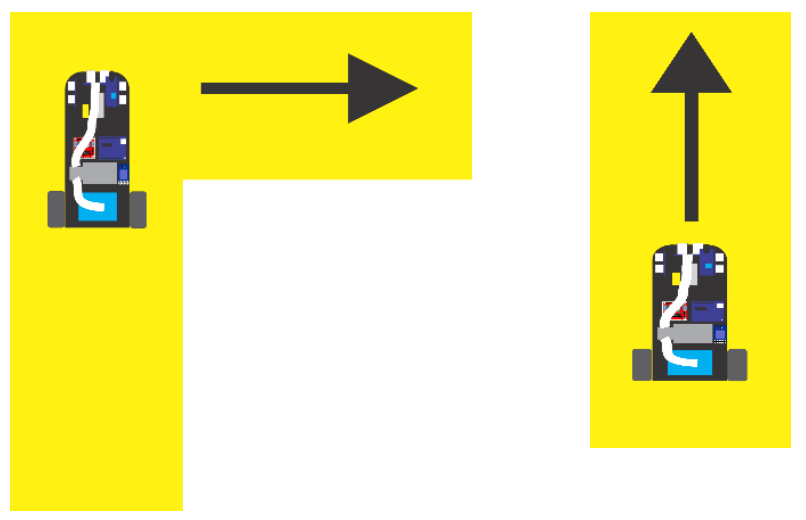

Gambar 5. Sensor Tengah robot belok kanan Gambar 6. Sensor kiri dan kanan mendeteksi adanya objek 
Dan jika sensor kiri mendeteksi adanya objek maka robot akan berjalan lurus dan sebaliknnya jika sensor kanan mendeteksi adanya objek maka robot juga akan berjalan lurus. Jika sensor tidak mendeteksi adanya objek maka robot akan berjalan lurus.

\section{Tahap Kedua}

Ditahap kedua robot di uji menggunakan sensor api untuk mendeteksi adanya api jika sensor mendeteksi adanya api maka lampu led pada sensor akan menyalasetelah sensor mendeteksi bahwa adanya api maka servo akan bergerak dari 30 derajat sampai 160 derajat dan pompa air akan menyemprotkan air, disini robot menggunakan modul sensor api yang bisa diatur untuk mendeteksi adanya api melalui pada sensor langsung tanpa harus diatur melalui koding.

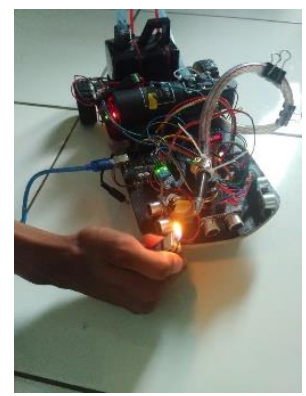

\section{Tahap Ketiga}

Gambar 7. Sensor api mendeteksi adanya api

Ditahap ketiga robot diuji menggunakan sensor ultrasonik, sensor api sebagai pendeteksi sumber api dan lilin sebagai sumber api dan menghasilkan robot akan berhenti bila mendeteksi adanya api dan menyemprotkan air pada api.

\section{Tahap Keempat}

Tahap ini dilakukan tes uji jalan dengan membawa air
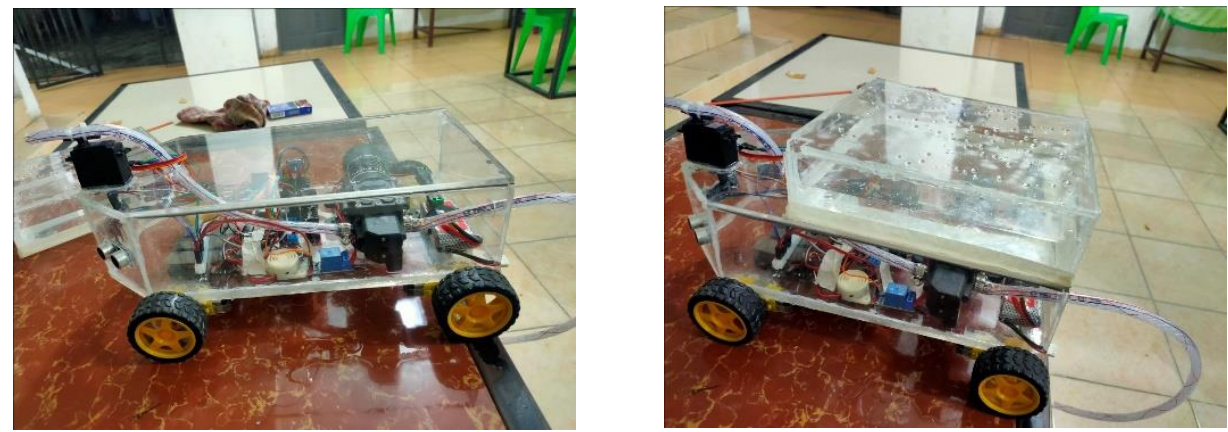

Gambar 8. Uji jalan robot membawa air

\section{KESIMPULAN}

Dari penelitian robot pemadam api menggunakan media air yang peneliti angkat sebagai judul penelitian, maka dapat ditarik kesimpulan sebagai berikut:

a. Terciptanya robot pemadam api menggunakan media air yang menggunakan sensor ultrasonic $H C$-SRO4 dan modul sensor api sebagai pendeteksi pada robot untuk mencari sumber api dan juga robot dapat memadamkan api tanpa harus dikontrol atau secara otomatis.

b. Dalam perancangan robot pemadam api ini robot hanya bisa memadamkan api berupa lilin menggunakan bantuan motor servo sebagai pengarah selang air.

c. Lilin yang digunakan dengan Panjang $15 \mathrm{~cm}$.

d. Dalam memadamkan api robot menggunakan pompa air sebagai media penyemprotan air. Adapun saran yang dapat diberikan dari penelitian yang telah dibuat oleh peneliti yaitu:

a. Kedepannya robot dibuat dapat menyiramkan air secara tepat pada sasaran.

b. Menambahkan media pengaturan melalui android.

c. Merubah sistem gerak robot menggunakan menggunakan kaki yang ditambahkan servo.

\section{REFERENCES}

[1] M. F. Faris, A. Triwiyatno, and I. Setiawan, "PERANCANGAN ARM MANIPULATOR 4 DOF DENGAN MENGGUNAKAN PENGENDALIAN CARTESIAN SPACE-TRAJECTORY PLANNING,” TRANSIENT, vol. 1, no. 4, pp. 152-157, 2012

[2] F. N. D. Furnama, "Mikrokontroler sandi morse dalam bentuk cahaya dan suara dengan bluetooth control android," Media J. Inform. vol. 9, no. 1, pp. 16-27, 2017. 
[3] M. Zikri and R. Khair, "Rancang Bangun Monitoring Polusi Udara Berbasis Arduino," J. Teknovasi J. Tek. dan Inov., vol. 5, no. 1, pp. 27-38, 2018.

[4] A. Çakir, N. Farooq, and E. Ezzulddin, "Fire-Extinguishing Robot Design by Using Arduino," IOSR J. Comput. Eng., vol. 18, no. 6 , pp. 113-119, 2016.

[5] Alfith, "PERANCANGAN ROBOT CERDAS PEMADAM API DENGAN SENSOR THERMAL ARRAY TPA 81 BERBASIS MICROCONTROLLER ARDUINO MEGA 2560,” J. Tek. Elektro ITP, vol. 5, no. 2, pp. 95-102, 2016

[6] M. S. Hasibuan, Syafriwel, and I. Idris, "Intelligent LPG Gas Leak Detection Tool with SMS Notification," J. Phys. Conf. Ser., vol. 1424 , no. $1,2019$. 